\title{
GAMBARAN STATUS KARIES MURID SEKOLAH DASAR NEGERI 48 MANADO BERDASARKAN STATUS SOSIAL EKONOMI ORANG TUA
}

\author{
${ }^{1}$ Jeiska Triska Tulangow \\ ${ }^{2}$ Ni Wayan Mariati \\ ${ }^{2}$ Christy Mintjelungan
}

\author{
${ }^{1}$ Kandidat Skripsi Program Studi Kedokteran Gigi Fakultas Kedokteran \\ Universitas Sam Ratulangi Manado \\ ${ }^{2}$ Program Studi Kedokteran Gigi Fakultas Kedokteran Universitas Sam Ratulangi Manado \\ Email: triskatulangow@Gmail.com
}

\begin{abstract}
Caries is a one cause of tooth loss. Caries occurs not only in adults but can occur in children. Tooth decay in children, can alter the growth of teeth at later ages. Socioeconomic status is one of the factors that affect health status, because the ends meet and to get a more desirable health care possible for socioeconomic group than in the low socioeconomic group. It is associated with a much greater interest in healthy living in higher socioeconomic groups that will influence health behavior. The purpose of this study is to get an overview of the status of caries Primary School pupil 48 Manado based on socio-economic status of parents. This research is a descriptive research. The study population was the disciple Elementary School 48 Manado aged 10-12 years, amounting to 83 people. study used total sampling. The primary data collection method is by examination of DMF-T and parents form an identity check. The results showed DMF-T index of 10-12 year olds in SDN 48 Manado has an average value of 3.38\%. Highest percentage of respondents who are respondents had moderate caries status of the 23 people (27.7\%) and respondents who had parents with secondary education are 61 people (73.5\%) with the highest percentage of caries in caries rate is currently amounts to 18 people. Children with low socioeconomic status have the DMF-T index higher than children of high socioeconomic status. This shows the lower the socioeconomic level of parents of respondents, the higher the DMF-T index child.
\end{abstract}

Keywords: caries, socio-economic status of parents, elementary school children.

\begin{abstract}
Abstrak: Karies merupakan salah satu penyebab hilangnya gigi. Kerusakan gigi pada anak, dapat merubah pertumbuhan gigi pada usia selanjutnya. Status sosial ekonomi merupakan salah satu faktor yang memengaruhi status kesehatan, sebab dalam memenuhi kebutuhan hidup dan untuk mendapatkan tempat pelayanan kesehatan yang diinginkan lebih memungkinkan bagi kelompok sosial ekonomi tinggi dibandingkan dengan kelompok sosial ekonomi rendah. Hal ini dikaitkan dengan lebih besarnya minat hidup sehat pada kelompok sosial ekonomi tinggi sehingga akan memengaruhi perilaku hidup sehat. Tujuan penelitian ini yaitu untuk mendapatkan gambaran status karies murid Sekolah Dasar Negeri 48 Manado berdasarkan status sosial ekonomi orang tua. Penelitian ini merupakan penelitian yang bersifat deskriptif. Populasi penelitian ini yaitu murid Sekolah Dasar Negeri 48 Manado yang berusia 10-12 tahun yang berjumlah 83 orang. Sampel penelitian digunakan total sampling. Metode pengambilan data secara primer yaitu dengan pemeriksaan DMF-T dan formulir pemeriksaan identitas orang tua. Hasil penelitian menunjukkan indeks DMF-T anak usia 10-12 tahun di SDN 48 Manado memiliki nilai rata-rata 3,38\%. Presentase responden terbanyak ialah responden yang memiliki status karies tingkat sedang yaitu 23 orang $(27,7 \%)$ dan responden yang memiliki orang tua dengan tingkat pendidikan menengah yaitu 61 orang (73,5\%) dengan presentase tingkat karies terbanyak yaitu pada tingkat karies sedang ialah berjumlah 18 orang. Anak dengan status sosial ekonomi rendah memiliki indeks DMF-T lebih tinggi dari anak yang status sosial ekonominya
\end{abstract}


86 Jurnal e-GiGi (eG), Volume 1, Nomor 2, September 2013, hlm. 85-93

tinggi. Hal ini menunjukkan semakin rendah tingkat sosial ekonomi orang tua responden, maka semakin tinggi indeks DMF-T anak.

Kata kunci: karies, status sosial ekonomi orang tua, anak SD.

Pembangunan kesehatan bertujuan meningkatkan kesadaran, kemauan dan kemampuan hidup sehat bagi setiap orang agar terwujud derajat kesehatan yang tinggi. Untuk mencapai tujuan tersebut diperlukan peningkatan sumber daya manusia serta kualitas hidup, peningkatan kesejahteraan keluarga dan masyarakat serta mempertinggi kesadaran masyarakat akan pentingnya hidup sehat. ${ }^{1}$ Hidup sehat merupakan bagian dari kualitas hidup, karena itu sehat tidak hanya secara fisik saja tetapi juga harus sehat mental dan kehidupan sosialnya. ${ }^{2}$

Kesehatan gigi dan mulut merupakan bagian dari kesehatan tubuh yang dapat memengaruhi kesehatan tubuh keseluruhan. Gigi merupakan bagian tubuh yang berfungsi untuk mengunyah, berbicara dan mempertahankan bentuk muka, sehingga penting untuk menjaga kesehatan gigi sedini mungkin agar dapat bertahan lama dalam rongga mulut. Masalah terbesar yang dihadapi penduduk Indonesia seperti juga di negara berkembang lainnya di bidang kesehatan gigi dan mulut yaitu karies gigi. ${ }^{3}$

Berdasarkan datadari WHO (2000) yang diperoleh dari enam wilayah WHO (AFRO, AMRO, EMRO, EURO, SEARO, WPRO) menunjukkan rata-rata pengalaman karies (DMFT) anak usia 12 tahun berkisar 2,4. Indeks karies di Indonesia sebagai salah satu negara SEARO (South East Asia Regional Offices) saat ini berkisar 2,2 untuk kelompok usia 12 tahun, sedangkan indeks target WHO tahun 2010 1,0. Berdasarkan Survei Kesehatan Rumah Tangga (SKRT, 2004), prevelansi karies di Indonesia mencapai 90,05\% dan ini tergolong tinggi. ${ }^{2}$

Berdasarkan Riset Kesehatan Dasar (Riskesdas) Indonesia (2007) menunjukkan bahwa Provinsi Sulawesi Utara merupakan salah satu dari lima provinsi dengan masalah gigi dan mulut tertinggi di Indonesia. ${ }^{4}$ Riset Kesehatan Dasar (Riskesdas) Provinsi Sulawesi Utara (2007) menunjukkan bahwa prevalensi karies aktif di Provinsi Sulawesi utara sebesar 52,6\% dengan prevalensi terbesar di kota Manado dengan prevalensi $70,2 \%{ }^{5}$ Hal ini membuktikan bahwa karies menjadi salah satu bukti tidak terawatnya kondisi gigi dan mulut masyarakat. ${ }^{2}$

Banyak penelitian menunjukkan bahwa prevalensi karies lebih tinggi pada anak yang berasal dari status sosial ekonomi rendah. Hal ini karena anak dari status ini banyak mengonsumsi makanan kariogenik, pengetahuan yang rendah akan kesehatan gigi dan mulut, jarang melakukan kunjungan pemeriksaan ke dokter gigi sehingga gigi tidak dirawat. ${ }^{6}$ Hal ini biasanya disebabkan berbagai faktor seperti isolasi keluarga, keuangan tidak memadai, ketidakpedulian orang tua, kurangnya penghargaan terhadap nilai kesehatan gigi dan mulut, dan bahkan kurangnya pemahaman orang tua akan pentingnya kesehatan gigi dan mulut. ${ }^{7}$

SDN 48 Manado ialah sekolah yang berada di pinggiran kota Manado tepatnya di kelurahan Sumompo, lokasinya berdekatan dengan tempat pembuangan akhir (TPA) Sumompo Kota Manado. SDN 48 Manado ini merupakan sekolah dengan murid yang lebih banyak memiliki status sosial ekonomi menengah ke bawah, dengan kegiatan Usaha Kesehatan Gigi Sekolah yang belum berjalan dengan baik. Penelitian ini dilakukan pada murid usia 10-12 tahun, karena pada usia tersebut diperkirakan gigi permanen telah erupsi kecuali gigi molar tiga. Berdasarkan fakta di atas maka penulis tertarik untuk meneliti "Gambaran Status Karies Murid Sekolah Dasar Negeri 48 Manado Berdasarkan Status Sosial Ekonomi Orang Tua".

\section{METODE PENELITIAN}

Penelitian ini merupakan penelitian deskriptif dengan pendekatan Cross sectional (potong lintang). Penelitian ini dilakukan di Sekolah Dasar Negeri 48 Manado pada bulan Oktober hingga November 2012. Populasi pada penelitian ini ialah anak usia 10-12 tahun yang sudah 
dalam periode gigi tetap dan terdaftar sebagai murid di Sekolah Dasar Negeri 48 Manado yang berdasarkan survei awal berjumlah 105 anak. Sampel yang dikehendaki ialah bagian dari populasi target yang akan diteliti secara langsung, dibatasi dalam kerangka sampel (sampling frame), yang memenuhi kriteria inklusi yaitu, tercatat dalam daftar siswa Sekolah Dasar Negeri 48 Manado tahun ajaran 2012/2013, berusia 1012 tahun, sudah dalam periode gigi tetap. Besar sampel dalam penelitian ini ialah yang termasuk dalam kriteria inklusi yaitu berjumlah 83 sampel. Pengambilan Sampel pada penelitian ini menggunakan metode total sampling, yaitu mengambil seluruh jumlah anak yang termasuk dalam sampling frame untuk dijadikan sampel. Variable penelitian dalam penelitian ini ialah status karies, status sosial ekonomi dan pendidikan orang tua. Definisi operasional dalam penelitian ini ialah: pengukuran status karies diukur dengan menggunakan pengukuran WHO yaitu: sangat rendah $0,0-1,1$; rendah 1,2-2,6; sedang 2,7-4,4; tinggi 4,5-6,5; sangat tinggi 6,6 keatas. Status sosial ekonomi diukur dari tingkat pendidikan orang tua, pekerjaan orang tua, pendapatan orang tua dan besar keluarga. Izin penelitian dimintakan kepada Kepala Sekolah SDN 48 Manado dan pada anak yang akan dilakukan pengambilan data DMFT diminta mengisi informed consent kepada masing-masing orang tua mereka, kemudian dilakukan seleksi sampel. Data diperoleh dengan cara mengunjungi dan meneliti langsung pada subjek penelitian di SDN 48 Manado dengan menggunakan formulir pemeriksaan dan DMFT untuk mengetahui status ekonomi orang tua dan status. Data diolah dan ditampilkan dalam bentuk tabel, untuk melihat gambaran status karies murid SDN 48 Manado berdasarkan status sosial ekonomi orang tua.

\section{HASIL PENELITIAN}

Karakteristik yang diamati pada responden dalam penelitian ini yaitu meliputi usia, jenis kelamin, pendidikan orang tua, pekerjaan orang tua, pendapatan orang tua dan besar keluarga.

\section{Distribusi responden berdasarkan usia}

Karakteristik usia responden dalam penelitian ini dibagi menjadi 3 kelompok usia yaitu dapat dilihat pada tabel 1 .

Tabel 1. Distribusi responden berdasarkan usia

\begin{tabular}{lcc}
\hline \multirow{2}{*}{ Usia } & \multicolumn{2}{c}{ Sampel } \\
\cline { 2 - 3 } & n & $\mathbf{\%}$ \\
\hline 10 tahun & 52 & 62,7 \\
11 tahun & 25 & 30,1 \\
12 tahun & 6 & 7,2 \\
Jumlah & 83 & 100,0 \\
\hline
\end{tabular}

Tabel 1 menunjukkan, sebagian besar responden memiliki usia 10 tahun yaitu berjumlah 52 orang $(62,7 \%)$ dan responden yang berusia 12 tahun menunjukan persentase yang paling sedikit yaitu berjumlah 6 orang $(7,2 \%)$.

\section{Distribusi responden berdasarkan jenis kelamin}

Karakteristik jenis kelamin responden dapat dilihat pada tabel 2 .

Tabel 2. Distribusi responden berdasarkan jenis kelamin

\begin{tabular}{lrc}
\hline \multirow{2}{*}{ Jenis Kelamin } & \multicolumn{2}{c}{ Sampel } \\
\cline { 2 - 3 } & $\mathbf{n}$ & $\mathbf{\%}$ \\
\hline Laki-laki & 47 & 56,6 \\
Perempuan & 36 & 43,4 \\
\multicolumn{1}{c}{ Jumlah } & 83 & 100,0 \\
\hline
\end{tabular}

Tabel 2 menunjukkan, sebagian besar responden dalam penelitian ini berjenis kelamin laki-laki yaitu berjumlah 47 orang $(56,6 \%)$ dan yang berjenis kelamin perempuan berjumlah 36 orang $(43,4 \%)$.

\section{Distribusi responden berdasarkan pendidikan orang tua}

Pendidikan terakhir orang tua responden dapat dilihat pada tabel 3 . 
88 Jurnal e-GiGi (eG), Volume 1, Nomor 2, September 2013, hlm. 85-93

Tabel 3. Distribusi responden berdasarkan pendidikan orang tua dan tingkat karies

\begin{tabular}{|c|c|c|c|c|c|c|c|}
\hline \multirow{2}{*}{ 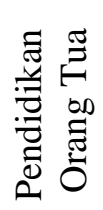 } & \multicolumn{5}{|c|}{ Tingkat Karies } & \multirow[b]{2}{*}{ 豞 } & \multirow[b]{2}{*}{$\%$} \\
\hline & 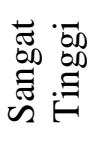 & $\begin{array}{l}\overrightarrow{00} \\
\stackrel{0}{0} \\
. \Xi\end{array}$ & 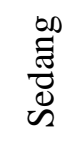 & 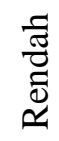 & 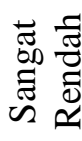 & & \\
\hline $\mathrm{R}$ & 3 & 5 & 4 & 4 & 1 & 17 & 20,5 \\
\hline M & 7 & 12 & 18 & 15 & 9 & 61 & 73,5 \\
\hline $\mathrm{T}$ & 0 & 0 & 1 & 2 & 2 & 5 & 6,0 \\
\hline Jlh & 10 & 17 & 23 & 21 & 12 & 83 & 100 \\
\hline
\end{tabular}

Ket: $\mathrm{R}=$ rendah, $\mathrm{M}=$ menengah, $\mathrm{T}=$ tinggi.

Tabel 3 menunjukkan, sebagian besar responden memiliki orang tua dengan tingkat pendidikan menengah yaitu 62 orang $(74,7 \%)$ dan responden yang memiliki orang tua dengan tingkat pendidikan tinggi menunjukkan presentase yang paling sedikit yaitu berjumlah 5 orang $(6,0 \%)$.

\section{Distribusi responden berdasarkan pekerjaan orang tua}

Karakteristik pekerjaan orang tua responden dapat dilihat pada tabel 4.

Tabel 4. Distribusi responden berdasarkan pekerjaan orang tua dan tingkat karies.

\begin{tabular}{|c|c|c|c|c|c|c|c|}
\hline \multirow[b]{2}{*}{ 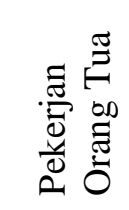 } & \multicolumn{5}{|c|}{ Tingkat Karies } & \multirow[b]{2}{*}{$\frac{\text { 夰 }}{\text { 皇 }}$} & \multirow[b]{2}{*}{$\%$} \\
\hline & 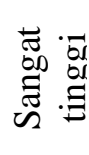 & 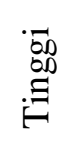 & 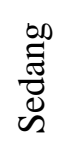 & 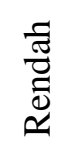 & 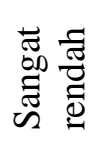 & & \\
\hline PNS & 0 & 0 & 3 & 6 & 2 & 11 & 13,25 \\
\hline $\begin{array}{l}\text { Wira- } \\
\text { swasta }\end{array}$ & 5 & 5 & 9 & 2 & 4 & 25 & 30,12 \\
\hline Buruh & 2 & 8 & 7 & 7 & 2 & 26 & 31,32 \\
\hline Petani & 0 & 0 & 0 & 0 & 1 & 1 & 1,20 \\
\hline $\begin{array}{l}\text { Peda- } \\
\text { gang }\end{array}$ & 0 & 0 & 0 & 2 & 2 & 4 & 4,82 \\
\hline Tukang & 2 & 1 & 2 & 2 & 0 & 7 & 8,43 \\
\hline Supir & 1 & 3 & 2 & 2 & 1 & 9 & 10,83 \\
\hline Jlh & 10 & 17 & 23 & 21 & 12 & 83 & 100 \\
\hline
\end{tabular}

Tabel 4 menunjukkan, sebagian besar responden memiliki orang tua yang bekerja sebagai buruh yaitu 26 orang (31,32\%) dan responden yang memiliki orang tua yang be- kerja sebagai petani menunjukkan presentase yang paling sedikit yaitu 1 orang (1,2\%).

\section{Distribusi responden berdasarkan pendapatan orang tua}

Karakteristik pendapatan orang tua responden yang di ukur berdasarkan UMR dapat dilihat pada tabel 5 .

Tabel 5. Distribusi responden berdasarkan pendapatan orang tua dan tingkat karies

\begin{tabular}{|c|c|c|c|c|c|c|c|}
\hline \multirow[b]{2}{*}{ 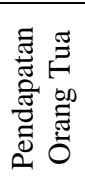 } & \multicolumn{5}{|c|}{ Tingkat Karies } & \multirow[b]{2}{*}{ 䒜 } & \multirow[b]{2}{*}{$\%$} \\
\hline & 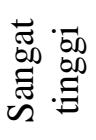 & 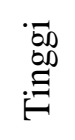 & $\begin{array}{l}\infty \\
\text { 茔 } \\
\text { के }\end{array}$ & 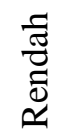 & 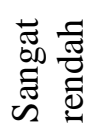 & & \\
\hline A & 1 & 7 & 10 & 13 & 7 & 38 & 45,8 \\
\hline B & 9 & 10 & 13 & 8 & 5 & 45 & 54,2 \\
\hline Jlh & 10 & 17 & 23 & 21 & 12 & 83 & 100 \\
\hline
\end{tabular}

Ket: $\mathrm{A}=$ diatas UMR, $\mathrm{B}=$ dibawah UMR.

Tabel 5 menunjukkan, responden dengan presentase terbanyak memiliki orang tua dengan pendapatan di bawah UMR yaitu 45 orang $(54,2 \%)$ dan 38 orang (45\%) lainnya memiliki orang tua dengan pendapatan di atas UMR.

\section{Distribusi responden berdasarkan besar keluarga}

Karakteristi besar keluarga responden dapat dilihat pada tabel 6 .

Tabel 6. Distribusi responden berdasarkan besar keluarga dan tingkat karies

\begin{tabular}{|c|c|c|c|c|c|c|c|}
\hline \multirow[b]{2}{*}{ 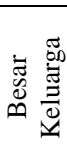 } & \multicolumn{5}{|c|}{ Tingkat Karies } & \multirow[b]{2}{*}{ 丞 } & \multirow[b]{2}{*}{$\%$} \\
\hline & $\begin{array}{l}\text { 总 } \\
\text { o. } \\
\text { 总 } \\
\text { 品 }\end{array}$ & 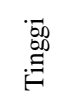 & $\begin{array}{l}\text { on } \\
\text { 志 } \\
\omega\end{array}$ & 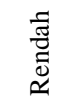 & 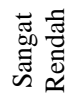 & & \\
\hline K & 3 & 10 & 4 & 12 & 4 & 33 & 39,8 \\
\hline $\mathrm{S}$ & 6 & 4 & 11 & 7 & 7 & 35 & 42,2 \\
\hline B & 1 & 3 & 8 & 2 & 1 & 15 & 18,0 \\
\hline Jlh & 10 & 17 & 23 & 21 & 12 & 83 & 100 \\
\hline
\end{tabular}

Ket: $\mathrm{K}=$ kecil, $\mathrm{S}=$ sedang, $\mathrm{B}=$ besar.

Tabel 6 menunjukkan, sebagian besar responden memiliki keluarga yang tergolong 
dalam kategori ukuran keluarga sedang yaitu 35 orang $(42,2 \%)$ dan responden yang memiliki keluarga yang tergolong dalam kategori keluarga besar menunjukkan presentase yang paling sedikit yaitu berjumlah 15 orang $(18,0 \%)$

\section{Hasil pemeriksaan status karies}

Status karies responden yang diukur dengan pengukuran DMF-T dapat dilihat pada tabel 9 .

Tabel 9. Distribusi responden berdasarkan tingkat karies

\begin{tabular}{ccc}
\hline \multirow{2}{*}{ Tingkat Karies } & \multicolumn{2}{c}{ Sampel } \\
\cline { 2 - 3 } & $\mathbf{n}$ & $\mathbf{\%}$ \\
\hline Sangat tinggi & 10 & 12,0 \\
Tinggi & 17 & 20,5 \\
Sedang & 23 & 27,7 \\
Rendah & 21 & 25,3 \\
Sangat rendah & 12 & 14,5 \\
\hline Jumlah & 83 & 100,0 \\
\hline
\end{tabular}

Tabel 9 menunjukkan, presentase responden terbanyak ialah responden yang memiliki status karies dengan tingkat karies yang sedang yaitu berjumlah 23 orang $(27,7 \%)$ dan responden yang memiliki status karies dengan tingkat karies yang sangat tinggi menunjukkan presentase yang paling sedikit yaitu berjumlah 10 orang (12,0\%).

\section{Hasil pemeriksaan responden berdasar- kan gambaran status karies dan status sosial ekonomi orang tua}

Hasil penelitian berdasarkan status karies dan status sosial ekonomi orang tua responden dalam penelitian ini ialah meliputi distribusi responden berdasarkan pendidikan orang tua dan tingkat karies.

Distribusi responden berdasarkan pendidikan orang tua yang dibagai dalam 3 tingkatan dan tingat karies yang dibagi dalam 5 tingkatan dapat dilihat pada tabel 10 .

Tabel 10. Distribusi responden berdasarkan pendidikan orang tua dan tingkat karies

\begin{tabular}{|c|c|c|c|c|c|c|c|}
\hline & \multicolumn{5}{|c|}{ Tingkat Karies } & \multirow[b]{2}{*}{$\mathrm{n}$} & \multirow[b]{2}{*}{$\%$} \\
\hline & 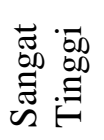 & $\begin{array}{l}\text { DD } \\
.00 \\
. \Xi\end{array}$ & $\begin{array}{l}\infty \\
\text { ప్ర్ } \\
\mathbb{W}\end{array}$ & 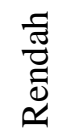 & 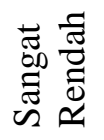 & & \\
\hline $\mathrm{R}$ & 3 & 5 & 4 & 4 & 1 & 17 & 20,5 \\
\hline M & 7 & 12 & 18 & 15 & 9 & 61 & 73,5 \\
\hline $\mathrm{T}$ & 0 & 0 & 1 & 2 & 2 & 5 & 6,0 \\
\hline Jlh & 10 & 17 & 23 & 21 & 12 & 83 & 100 \\
\hline
\end{tabular}

Ket: $\mathrm{R}=$ rendah, $\mathrm{M}=$ =menengah, $\mathrm{T}=$ tinggi.

Tabel 10 menunjukkan, dari 17 responden (20,5\%) yang memiliki orang tua dengan tingkat pendidikan yang rendah memiliki presentase terbanyak dengan status karies pada tingkat karies yang tinggi yaitu berjumlah 5 orang. Dari 61 responden $(73,5 \%)$ yang memiliki orang tua dengan tingkat pendidikan menengah menunjukkan bahwa, presentase terbanyak ialah terdapat pada status karies dengan tingkat karies yang sedang yaitu berjumlah 18 orang. Dari 5 responden $(6,0 \%)$ yang memiliki orang tua dengan tingkat pendidikan yang tinggi, menunjukkan presentase terbanyak ialah yang memiliki status karies dengan tingkat karies yang rendah yaitu berjumlah 2 orang dan pada tingkat karies yang sangat rendah juga berjumlah 2 orang.

\section{BAHASAN}

\section{Distribusi Responden Berdasarkan Jenis Kelamin}

Hasil penelitian berdasarkan jenis kelamin yang dilakukan pada murid Sekolah Dasar Negeri 48 Manado menunjukkan, distribusi responden terbanyak berjenis kelamin laki-laki yaitu berjumlah 47 orang (56,6\%), dan yang berjenis kelamin perempuan yaitu berjumlah 36 orang $(43,4 \%)$.

Anak-anak mempunyai resiko karies yang tinggi ketika gigi mereka baru erupsi karena sulitnya membersihkan gigi yang sedang erupsi sampai gigi tersebut mencapai dataran oklusal dan beroklusi dengan gigi antagonisnya, sedangkan orang tua lebih beresiko terhadap terjadinya karies akar. ${ }^{2}$

Selama masa kanak-kanak dan remaja, wanita menunjukkan nilai DMF yang lebih tinggi dari pada pria. Walaupun demikian, 
umumnya kebersihan rongga mulut wanita lebih baik sehingga komponen gigi yang hilang $\mathrm{M}$ (missing) lebih sedikit dari pada pria. Sebaliknya, pria mempunyai komponen $\mathrm{F}$ (filling) yang lebih banyak dalam indeks DMF. ${ }^{6}$

\section{Distribusi responden berdasarkan tingkat pendidikan orang tua}

Menurut distribusi responden berdasarkan tingkat pendidikan didapatkan bahwa, sebagian besar responden memiliki orang tua dengan tingkat pendidikan menengah yaitu 62 orang (74,7\%).

Semakin tinggi tingkat pendidikan formal seseorang, maka semakin baik pengetahuan dan sikap perilaku hidup sehat, bahkan semakin mudah untuk memperoleh pekerjaan sehingga semakin banyak pula penghasilan yang diperoleh untuk memenuhi kebutuhan kesehatan. Sebaliknya, pendidikan yang kurang akan menghambat perkembangan sikap seseorang terhadap nilai-nilai yang baru dikenal. ${ }^{2}$

\section{Distribusi responden berdasarkan peker- jaan orang tua}

Berdasarkan distribusi responden pekerjaan orang tua menunjukkan, sebagian besar responden memiliki orang tua yang bekerja sebagai buruh yaitu sebanyak 26 orang (31,32\%).

Pekerjaan ialah simbol status seseorang di masyarakat yang merupakan jembatan, untuk memperoleh uang dalam memenuhi kebutuhan hidup dan untuk mendapatkan tempat pelayanan kesehatan yang diinginkan.

Secara tidak langsung, pekerjaan orang tua memiliki hubungan dengan kejadian karies gigi. Faktor kesibukan dalam pekerjaan membuat orang tua memiliki waktu yang terbatas dalam mengawasi pertumbuhan perkembangan dan kesehatan anak. Pekerjaan juga merupakan jembatan untuk memperoleh uang dalam memenuhi kebutuhan hidup dan mendapatkan tempat pelayanan kesehatan yang diinginkan, sehingga semakin baik jenis pekerjaan seseorang maka semakin terpenuhi pula kebutuhan hidup dan kesehatan keluarga. Hasil penelitian yang dilakukan oleh Sihite (2012) menunjukkan 49\% anak mengalami karies gigi dan DMFT rata-rata 1,01 dan berdasarkan perhitungan statistik terdapat hubungan bermakna antara jenis pekerjaan orang tua dengan prevalensi bebas karies gigi anak $(\mathrm{p}=0,001) .{ }^{8}$ Menurut Kent dan Blinkhorn, pekerjaan menunjukkan kelas sosial tertentu dimana penelitian menunjukkan adanya penurunan dalam insidensi karies khususnya pada anak-anak dewasa muda, terutama pada anak dari kelompok sosial ekonomi tinggi. Hal ini menyatakan bahwa status sosial ekonomi juga dapat memengaruhi status kesehatan. ${ }^{9}$

\section{Distribusi responden berdasarkan pen- dapatan orang tua}

Hasil penelitian menunjukkan sebagian besar orang tua responden memiliki pendapatan di bawah UMR yaitu berjumlah 45 orang $(54,2 \%)$.

Pendapatan akan memengaruhi gaya hidup seseorang, sebab seseorang atau keluarga yang mempunyai pendapatan yang tinggi akan memraktikkan gaya hidup yang mewah misalnya lebih komsumtif karena mereka lebih mampu untuk membeli semua yang dibutuhkan bila dibandingkan dengan keluarga yang kelas ekonominya di bawah. Anak dari keluarga yang memiliki penghasilan menengah ke atas lebih cenderung mengonsumsi makanan yang mengandung kariogenik, karena anak dari keluarga ini lebih mampu untuk membeli makanan yang banyak mengandung kariogenik. $^{10}$

\section{Distribusi responden berdasarkan besar keluarga}

Distribusi responden berdasarkan besar keluarga menunjukan bahwa sebagian besar responden memiliki keluarga yang tergolong dalam kategori keluarga sedang yaitu berjumlah 35 orang (42,2\%).

Besar keluarga akan sangat memengaruhi pengeluaran dalam sebuah keluarga. Semakin besar ukuran sebuah keluarga maka akan semakin besar pengeluaran atau 
anggaran yang di butuhkan, jika pendapatan keluarga hanya kecil maka distribusi pengeluaran untuk masing-masing personal akan semakin kecil.

\section{Distribusi responden berdasarkan tingkat karies}

Menurut data distribusi responden menunjukkan bahwa, sebagian besar responden memiliki status karies dengan tingkat karies yang sedang yaitu berjumlah 23 orang (27,7\%).

Karies gigi merupakan penyakit jaringan keras gigi yaitu email, dentin dan sementum yang disebabkan oleh aktivitas mikroorganisme yang ada dalam suatu karbohidrat yang diragikan dalam makanan. ${ }^{11}$

Penyakit ini bersifat progresif dan jika tidak diobati dapat berkembang sampai ke pulpa dan lubang yang telah terbentuk tidak dapat diperbaiki kembali oleh tubuh melalui proses penyembuhan dan menyebabkan peradangan pada pulpa, sehingga menimbulkan rasa sakit dan ketidaknyamanan dan bahkan sampai kehilangan vitalitas kemudian kehilangan gigi. ${ }^{12}$

\section{Distribusi responden berdasarkan pen- didikan orang tua dan tingkat karies}

Data hasil distribusi berdasarkan pendidikan orang tua menunjukkan bahwa, 17 responden (20,5\%) yang memiliki orang tua dengan tingkat pendidikan yang rendah memiliki presentase terbanyak dengan status karies yang tinggi yaitu berjumlah 5 orang. Dari 61 responden $(73,5 \%)$ yang memiliki orang tua dengan tingkat pendidikan menengah menunjukkan bahwa, presentase terbanyak ialah yang memiliki status karies dengan tingkat karies yang sedang yaitu berjumlah 18 orang. Dari 5 responden (6,0\%) yang memiliki orang tua dengan tingkat pendidikan yang tinggi, menunjukkan presentase terbanyak ialah pada status karies dengan tingkat kares yang rendah yaitu berjumlah 2 orang dan pada status karies dengan tingkat karies yang sangat rendah juga berjumlah 2 orang.

Pendidikan sangat berhubungan erat dengan pengetahuan, terutama pengetahuan tentang kesehatan. Seseorang yang memiliki pendidikan tinggi diasumsikan memiliki pengetahuan yang baik. Menurut Tirthankar, pendidikan merupakan faktor kedua terbesar dari faktor sosial ekonomi yang memengaruhi status kesehatan. ${ }^{2}$ Semakin tinggi pendidikan formal seseorang maka semakin baik pengetahuan dan sikap tentang kesehatan yang memengaruhi prilaku hidup sehat, dengan demikian juga semakin mudah dalam memperoleh pekerjaan dan semakin banyak penghasilan yang diperoleh untuk memenuhi kebutuhan kesehatan. Penelitian yang dilakukan oleh Sihite (2012) menunjukkan 49\% anak mengalami karies gigi dan DMFT rata-rata 1,01 dan berdasarkan perhitungan statistik terdapat hubungan yang bermakna antara tingkat pendidikan orang tua dengan prevalensi bebas karies gigi anak $(\mathrm{p}=0,007){ }^{8}$

Merujuk pada tingkat pendidikan orang tua dapat diasumsikan bahwa semakin tinggi pendidikan orang tua maka pengetahuan tentang perawatan gigi pada anak akan semakin tinggi. Sehingga orang tua yang memiliki tingkat pendidikan tinggi cenderung mengajarkan perilaku hidup bersih dan sehat sehingga kesehatan gigi anak mereka tetap terjaga dengan baik.

Penyakit gigi dan mulut memiliki dampak terhadap kualitas hidup. Dampak yang segera terlihat yaitu pada anak sekolah dimana dapat menyebabkan kehilangan hari sekolah. Karies gigi memiliki dampak luas, meliputi keterbatasan fungsi, rasa sakit fisik, ketidaknyamanan psikis, disabilitas fisik, psikis dan sosial. ${ }^{9}$ Orang tua mempunyai peran penting dalam membina perilaku anaknya sejak dini. Robinson mengidentifikasikan orang tua merupakan variabel intervensi yang paling persuatif dalam program kesehatan gigi, dan mempunyai pengaruh langsung terhadap kebiasaan prilaku sehat. ${ }^{13}$ Menurut Budiharto, kontribusi yang berperan dalam perilaku orang tua terhadap kesehatan gigi anak yaitu sosial ekonomi keluarga. ${ }^{14}$ Faktor sosial ekonomi penting karena memengaruhi minat dan perilaku hidup sehat, serta pentingnya peran orang tua dalam perilaku kesehatan, sebab mengingat anak usia sekolah masih 
92 Jurnal e-GiGi (eG), Volume 1, Nomor 2, September 2013, hlm. 85-93

bergantung pada orang tua. Orang tua hendaknya memerhatikan kesehatan gigi dan mulut anak sehingga gigi asli dapat dipertahankan seumur hidup agar kesehatan gigi dengan fungsi optimalnya dapat dinikmati. $^{9}$

\section{SIMPULAN}

Berdasarkan kategori status karies dari 83 responden menunjukkan bahwa, presentase terbanyak ialah responden yang memiliki status karies dengan tingkat karies yang sedang yaitu berjumlah 23 orang (27,7\%), dan presentase paling sedikit ialah responden yang memiliki status karies dengan tingkat karies yang sangat tinggi yaitu berjumlah 10 orang 12,0\%).

Hasil penelitian berdasarkan pendidikan orang tua menunjukkan, dari 83 responden yang menjadi subjek dalam penelitian ini sebagian besar memiliki orang tua dengan tingkat pendidikan menengah yaitu berjumlah 61 responden (73,5\%), dengan presentase terbanyak ialah yang memiliki status karies dengan tingkat karies yang sedang yaitu berjumlah 18 orang. Responden paling sedikit ialah responden yang memiliki orang tua dengan tingkat pendidikan yang tinggi yaitu berjumlah 5 responden (6,0\%) dengan presentase terbanyak ialah yang memiliki status karies dengan tingkat karies yang rendah yaitu berjumlah 2 responden dan yang memiliki status karies dengan tingkat karies yang sangat rendah yaitu juga berjumlah 2 responden.

\section{DAFTAR PUSTAKA}

1. Sihombing J. Karakteristik Penderita Karies Gigi yang berobat di Rumah Sakit Umum Dr. Pirngadi. Medan: USU. [Online]. 2009 [cited: April 2012]. Available from: URL: http://repository. usu.ac.id/bitstream/123456789/14660/1/09 E01300.pdf.

2. Pintauli S, Hamada T. Menuju gigi dan mulut sehat pencegahan dan pemeliharaan. Medan: USU Pres, 2008; p.4-24.

3. Jamil JA. Hubungan Antara Kebiasaan Mengkonsumsi Jajanan Dengan Pengalaman Karies Pada Gigi Susu Anak
Usia 4-6 Tahun Di TK Medan. Medan: USU Pres, 2011; p.1.

4. Depkes. Laporan hasil kesehatan dasar (RISKESDAS) Indonesia tahun 2007. Badan penelitian dan pengembangan kesehatan. Jakarta: Departemen Kesehatan RI, 2008; p.131-132.

5. Depkes. Laporan hasil kesehatan dasar (RISKESDAS) Provinsi Sulawesi Utara tahun 2007. Badan penelitian dan pengembangan kesehatan. Manado: Departemen Kesehatan RI, 2008; h.89.

6. Angela A. Pencegahan primer pada anak yang berisiko karies tinggi. Departemen Pedodonsia, Medan: USU Dent J [serialOnline]. 2005. [cited: September 2012]; 38(3):130-134. Available from: URL: http://skp.unair.ac.id/repository/ jurnalpdf/jurnal 652.pdf

7. Pertiwi ASP, Sasmita IS, Suptarini R. Gambaran pola karies gigi permanen ditinjau dari dental neglect siswa kelas 5-6 SDN Cikudayasa kec. Cileunyi Kabupaten Bandung. Bandung: Unpad, 2007; p.4.

8. Sihite, John H. Hubungan tingkat sosial ekonomi orang tua dengan status bebas karies pada anak usia 7-11 tahun. Medan: Universitas Sumatera Utara [Online]. 2012 [cited: April 2013]. Available from: URL: http://repository.usu.ac.id/handle/12345678 9/33762

9. Tampubolon NS. Dampak karies gigi dan penyakit periodontal terhadap kualitas hidup. Pidato Pengukuhan Jabatan Guru Besar Tetap Dalam Bidang Ilmu Kedokteran Gigi Pencegahan / Kesehatan Gigi Masyarakat pada Fakultas Kedokteran Gigi Universitas Sumatera Utara, Medan [Online]. 2005 [cited: April 2013]. Available from: URL: http://ebookuniver se.net/download.php?file $=62465 \mathrm{a} 46665178$ $39576 \mathrm{e} 56364148356 \mathrm{~d} 56413 \mathrm{~d} 3 \mathrm{~d} \& \mathrm{q}=0$

10. Lilik, Hidayanti. Hubungan karakteristik keluarga dan kebiasaan konsumsi makanan kariogenik dengan keparahan karies gigi anak sekolah dasar survei pada anak sekolah dasar di Kecamatan Cihideung Kota Tasikmalaya. Universitas Diponegoro [Online]. 2010 [cited: April 2013]. Available from: URL: hhttp://eprints.undip.ac.id/18225/

11. Debnath T. Ashok's public health and preventive dentistr (Second Edition). India: AITBS publishers dan distributors (regd), 2002; p.30-8.

12. Samarrai SEI. Etiology of Dental Caries. 
Baghdad: University of Baghdad, 2011; p.1.

13. Suwargiani AA. Indeks def-t dan DMF-T masyarakat Desa Cipondoh dan Desa Mekarsari Kecamatan Tirtamulya Kabupaten Karawang. Bandung:
Universitas Padjajaran, 2008; p.14-6.

14. Budiharto. Kontribusi umur, pendidikan, jumlah anak, status ekonomi keluarga, pemanfaatan fasilitas kesehatan gigi dan pendidikan kesehatan gigi terhadap perilaku ibu. JKGUI. 1998; 5(2):92-108. 